\title{
Pattern and determinants of contraceptive use among the Muslim women in Wajir and Lamu counties in Kenya: A cross-sectional study
}

Batula Abdi ( $\sim$ abdi@unfpa.org )

United Nations population Fund

Jerry Okal

Population Council

Gamal Serour

Al Azhar University

Vincent Were

Kenya Medical Research Institute

Marleen Temmerman

Aga Khan University Nairobi

Peter Gichangi

Ghent University

\section{Research Article}

Keywords: Family Planning, Contraceptives, Muslim communities

Posted Date: December 13th, 2022

DOl: https://doi.org/10.21203/rs.3.rs-1278608/v2

License: (9) (i) This work is licensed under a Creative Commons Attribution 4.0 International License.

Read Full License 


\section{Abstract}

Improving access to family planning (FP) is associated with positive health benefits that includes averting nearly a third of all maternal deaths and $10 \%$ of childhood deaths. Kenya has made great strides in improving access to family planning services. However, amid this considerable progress, regional variation has been noted.

\section{Methods}

We conducted a cross-sectional study that involved 663 Muslim women of reproductive age (15-49 years) from Wajir and Lamu counties in Kenya between March and October 2018. Eligible women were interviewed using a semi-structured questionnaire containing socio-demographic information and history of family planning use. Simple and multiple logistic regression were used to identify determinants of family planning use. The results were presented as Crude Odds Ratio crude (COR) and Adjusted Odds Ratio (AOR) ratios at $95 \%$ confidence interval. A p-value of 0.05 was considered statistically significant.

Results

Of the 663 Muslim women of reproductive age consenting to participate in the study, $51.5 \%, n=342$ and $48.5 \%, n=321$ were from Lamu and Wajir County, respectively. The prevalence of women currently using contraceptive was 18.6 percent $(n=123)$. In Lamu, the prevalence was $32.8 \%$, while in Wajir, it was 3.4 percent.

The determinants of current contraceptive use in Lamu include; marital status, age at marriage employment status, discussion with a partner on FP, acceptability of FP in Culture, and willingness to obtain information on FP. While in Wajir, determinants of current contraceptive use were education, Family planning allowed in Islam.

\section{Conclusions}

Our study found moderately high use of contraceptives among Muslim women of reproductive age in Lamu county and very low contraceptive use among women in Wajir. There is need for family planning programs to address issues of male involvement in reproductive health given the patriarchal nature of the two communities. It is critical for the government to invest in women and girls education to enhance their ability to make informed decisions; particularly in Wajir where FP uptake is low with low education attainment. Further, our findings highlight the need for culturally appropriate messages and involvement of religious leaders to demystify the myths and misconception around family planning and Islam.

\section{Introduction}

Globally there has been clear commitment to improve access to quality family planning services. The 2030 agenda for sustainable development has two relevant targets to family planning under the broader goals of health and wellbeing (SDG 3) and on gender equality and the empowerment of women and girls 
( SDG 5) (1). Despite impressive progress globally, contraceptive use in Africa is worryingly low at $36 \%$ $(1,2)$ compared to the Caribbean, North America, and Latin America that have a prevalence rate of over $70 \%(1)$

The public health importance of family planning is well documented. Improving access to family planning in countries with high fertility rates can potentially reduce poverty and hunger and avert $32 \%$ of all maternal deaths and nearly $10 \%$ of childhood deaths (3). Family planning has benefits that go beyond the health sector. Ensuring couples and individuals have a choice to decide how many and how frequent they will have children will considerably contribute to women's empowerment, the achievement of universal primary schooling, and long-term environmental sustainability (4)

Kenya has made great strides in improving access to family planning services. The number of women using contraceptives has tremendously increased over time. In the past decade, the Contraceptive Prevalence Rate (CPR) increased from 32\% in 2003 to 39\% in 2009 and 58\% in 2014 [4]. Despite the increase in CPR, there has been limited change in unmet need for Family Planning (FP), from $28 \%$ in 1998 to $26 \%$ in 2009 , and $18 \%$ in 2014 (5). In spite of this progress, there are huge regional variations in CPR. The CPR in some of the regions in Kenya (including the central region with a CPR of $76 \%$ ) is comparable to that of developed countries; however, some regions (such as North Eastern) have recorded CPR as low as $3.4 \%$ (5). Wajir County has a CPR of $2 \%$, which is the lowest in the country. On the other hand, Wajir county has the highest TFR in Kenya of eight children per woman (5) while Lamu County has a CPR of $42 \%$ and a TFR of 4 children per woman (5).

Studies have examined factors that determine the use of FP. The predominant factors include age, education, place of residence; social-economic status; spousal communication and religion (5-8). Several studies have established that FP utilization is highest among women who are educated and those aged 25-35 (9-11). It has also been cited that girls education has a knock-on effect on age at first marriage, entrance into the paying labour market, and still education correlates with fertility reduction (12-14). Similarly, women who are economically empowered or who are employed or have a source of income are more likely to use FP $(8,15)$. Additionally, evidence shows that spousal communication has a positive impact on FP use (16-18).

Several studies have been conducted to establish whether contraceptive use differed with religious beliefs. While this has been the centre of debate with regard to FP use, a qualitative study conducted in Lamu and Wajir County shows that there is a widespread misinterpretation of Islam with regards to the permissibility of contraceptive use (19). Studies have shown that Islam permits family planning; it is evident from the various fatwas[10] (declarations) in the Muslim countries and evidence from various sources of Islamic sharia[11] (law) that family planning is permitted in Islam $(20,21)$. Despite the evidence on the permissibility of contraception in Islam, there is still a misconception among many Muslim communities that Islam does not permit contraception $(19,20,22)$.

Apart from the national surveys, such as demographic health surveys, there is a paucity of data on determinants of family planning uptake among the Muslim community in Kenya. Furthermore, the Kenya 
Demographic Health Survey (KDHS) does not provide a detailed analysis of why the uptake of FP is so low among Muslims. With this background in mind, this study sought to establish the determinants of contraceptive use in the two predominant Muslim settings of Lamu and Wajir that have varying contraceptive uptake. Stdies have shown that uptake of family planning could be influenced by religious beliefs and cultural practices. Understanding the determinants of contraceptive use in these settings is important for informing the design of culturally appropriate family planning programmes.

[10] Fatwa- authoritative legal opinion or learned interpretation by a qualified jurist regarding issues pertaining to Islamic Shariah.

[11] Sources of Islamic law (Shariah): The primary sources of Shariah are the Quran (Islam's holy book) and the Sunnah, the sayings and deeds of the Prophet Mohammad and his Companions. Also based on the Quran and Sunnah but subordinate to them are two other sources for Shariah: the consensus of Islamic jurists (ijmae) and analogy (qiyas).

\section{Methods}

\section{Study Design And Setting}

This was an analytical cross-sectional household survey conducted between March and October 2018, in Wajir and Lamu counties. Two sub-counties were purposefully selected in each county, namely Wajir East and Wajir North in Wajir County, and Lamu West and Lamu East in Lamu County.

\section{Study Setting}

Wajir county is ranked as one of the poorest in the country with as many as $76 \%$ of its residents having low education levels and only $4 \%$ have completed secondary level education or higher (23). In Lamu, nearly a third of the county's residents live below the poverty line with only $13 \%$ having competed secondary education (23). Lamu County is a predominantly coastal community of the Swahili ethnic group while Wajir County is inhabited primarily by pastoralist Somalis.

\section{Sample Size And Sampling Procedure}

Data collection involved administration of a semi structured questionnaire to female respondents aged 15-49 years in their households (Additional file 1). We calculated samples size using formulae shown below adopted from UNICEF's Multiple Indicator Cluster Surveys (MICS) (24)

$$
n=\frac{4 \times r \times(1-r) \times \text { deff }}{(R M E \times r)^{2} \times p b \times \text { AveSize } \times R R}
$$


Where is $\mathrm{n}$ is the required sample size (number of households); 4 is a factor to achieve the 95 percent level of confidence; $r$ is the predicted or estimated value of the indicator in target population; deff is the design effect; RR is the response rate; $\mathrm{pb}$ is the proportion of the target subpopulation in total population (upon which the indicator, $r$, is based); AveSize is the average household size (that is, average number of persons per household); RME is the relative margin of error to be tolerated the $95 \%$ level of confidence; Currently, the target for the RME is generally is $12 \%$. The total sample size for all domains was 350 in each county.

\section{Sampling Strategy}

The study used multi-stage sampling in combination with stratified and systematic random sampling to selected the respondents. In the first stage, each sub-county was stratified into constituent wards, sublocations and further into villages. The village comprised the primary sampling units (PSU). From each village, we obtained a list of all households from the chief's office. In the second stage, households were selected from the household listing in each selected primary sampling units (PSU) using systematic sampling with a random start. All eligible household members aged 15-49 within the selected households were eligible for the study. However, only one woman of reproductive age was interviewed per household. In households where more than one woman of reproductive age 15-49 resides, a Kish grid[12] was used to select one respondent from that household. We excluded those who did not provide consent, and women aged $<18$ (unless they were emancipated minors) or $>49$ years old. Although minors below 18 were part of the inclusion criteria there were no minors interviewed.

\section{Data Management And Statistical Analysis}

Data were double entered and cleaned in epi infoTM 7 before statistical analyses. All analyses were conducted in STATA software version 15 (StataCorp. 2017). Descriptive statistics were used to summarise data whilst tables and figures were used for data presentation. Binary and multiple logistic regression analysis was used to identify the determinants of family planning use. Odds ratio with their corresponding 95\% Confidence Intervals were used to determine magnitude and directions of the statistical associations in both bivariate and multivariable analyses. P-value was considered statistically significant at $5 \%$ level.

\section{Outcome Variable}

The study had one outcome variable which is current use of modern contraceptive method. They were coded as 1 "current use" and 0 otherwise. Current use was defined as women who were currently using any modern contraceptive method.

\section{Explanatory Variables}


The explanatory variables were chosen based on expert opinion or prior knowledge. They included; the age of the participant, level of education, marital status, age at marriage, employment status, discussion with a spouse, ever given birth, family planning awareness, number of living children, acceptability in culture, FP allowed in Islam and willingness to obtain information on FP.

\section{Data Analysis}

A descriptive analysis was carried out to establish the level of current use, method preference and reasons for non-use after which frequency and $95 \%$ confidence intervals were reported. The binary logistic regression analysis was used to determine the determinants associated with family planning use. Crude Odds ratios (COR) and Adjusted Odds Ratio (AOR) with their corresponding 95\% confidence intervals were used to determine the magnitude and directions of the statistical associations in both simple and multivariable analyses. A p-value of $<0.05$ was considered statistically significant.

\section{Ethical Considerations}

Ethical approval for the study was obtained from the Research Ethics Committee of the Aga Khan University, Nairobi (2016/REC-56 (v3)). We also obtained a research permit from the National Commission for Science, Technology and Innovation (NACOSTI/P/18/14340/20946) to facilitate the conduct of research activities in the community. All participants provided written informed consent. Regarding minors below the age of 18 years only married adolescents, who are considered as emancipated, were included.

[12] The Kish grid is a method for selecting members within a household to be interviewed. It uses a preassigned table of random numbers to find the person to be interviewed.

\section{Results}

\section{Socio-demographic and economic characteristics of the study participants}

Of the 663 women of reproductive age consented to participate in the study,342 (51.5\%) and 321 (48.5\%) came from Lamu and Wajir County respectively. The median age of study participants was 30 years (IQR, 24-35) in Lamu and 28 (IQR, 25-34) in Wajir. The majority of the study participants (Lamu $51.6 \%$ vs Wajir $48.4 \%$ ) in the two Counties were aged between 25 to 34 years of age. There was a significant difference by education level with the majority $(72.2 \%)$ of the participant in Lamu County having secondary education and above while in Wajir County majority $(54.2 \%)$ had no formal education. In Lamu $127(44.2 \%)$ were married at the age of 15-19 years while in Wajir majority were married at the age of 20 to 24 years. A significant difference in the distribution of study participants by age group (Table 1) 
Table 1

Socio-demographic and economic characteristics of study participants $(N=663)$.

\section{County}

Lamu $\mathrm{n}=\mathbf{( 3 4 2 )} \quad$ Wajir $\mathrm{n}=\mathbf{( 3 2 1 )} \quad$ P-value

Characteristic

Median (IQR), years

$30(24-35)$

$28(25-34)$

0.427

Age categories (years):

$\mathrm{n}(\%)$

n (\%)

$18-24$

97 (28.6)

79 (24.6)

0.126

25-34

154 (45.0)

168 (52.3)

$35-44$

80 (23.3)

70 (21.8)

$45+$

$11(3.2)$

4 (1.2)

Highest level of education:

\begin{tabular}{|c|c|c|c|}
\hline None/Madrassa & $25(7.31)$ & $171(53.3)$ & \multirow[t]{3}{*}{$<0.0001$} \\
\hline Primary & $70(20.5)$ & $71(22.1)$ & \\
\hline Secondary and above & $247(72.2)$ & $79(24.6)$ & \\
\hline \multicolumn{4}{|l|}{ Marital status: } \\
\hline Married & $287(83.9)$ & $265(82.6)$ & \multirow[t]{2}{*}{0.638} \\
\hline Not Married & $55(16.1)$ & $56(17.4)$ & \\
\hline \multicolumn{4}{|l|}{ Age at marriage -years $(n=552)$ : } \\
\hline$<15$ & $17(5.9)$ & $0(0.0)$ & \multirow[t]{4}{*}{$<0.0001$} \\
\hline $15-19$ & $127(44.2)$ & $84(31.7)$ & \\
\hline $20-24$ & $109(37.9)$ & $129(48.6)$ & \\
\hline $25-34$ & $33(11.5)$ & $52(19.6)$ & \\
\hline $35+$ & $1(0.3)$ & $0(0.0)$ & \\
\hline Age at married (Mean $\pm S D$, year) & $19.7(3.7)$ & $21.4(3.3)$ & $<0.0001$ \\
\hline \multicolumn{4}{|l|}{ Currently employed: } \\
\hline Yes & $58(16.9)$ & $52(16.2)$ & \multirow[t]{2}{*}{0.793} \\
\hline No & $284(83.1)$ & $269(83.8)$ & \\
\hline
\end{tabular}

**values in bold are statistically significant at $p$-value $<0.05$ 


\section{Fp Use By Methods}

Figure 1 shows the type of family planning methods used by the participants county of residence. Injectable (61.8\% vs. 38.6\%) were commonly used in Lamu than Wajir whereas pills were commonly used in Wajir (66.7\%). Moreover, implants were mostly used in Lamu (21.6\%) than Wajir (1.8\%). Of the 271 participants who reported to have ever used a family planning method(s), $14(2.1 \%)$ reported using dual contraceptives (i.e. condoms and any other modern contraceptive method). Nonetheless, about $23 \%$ $(61 / 271)$ of the study participants reported using a long-term modern contraceptive method.

\section{Percentage Of Women Currently Using Family Planning}

Table 2 shows the current use of family planning in the two study sites. The percentage of women currently using family planning was $18.6 \%(n=123)$. In Lamu, the percentage was $32.7 \%$ while in Wajir, it was 3.4 per cent. In Lamu, current use of FP was highest among women between 25 and 34 years with a percentage of 42.9(35.2-50.8), while in Wajir, FP use was prevalent among women above 45 years 25.0(2.4-82.1) per cent. In Lamu, current FP use was highest among women who had attained secondary education with a percentage of 34.3(28.9-40.2), this also applied to Wajir 9.8(4.9-18.4). The current use of FP was highest among married women in both counties; 35.2(29.9-40.9) in Lamu and 3.8(2.0-6.9) in Wajir. In Lamu and Wajir, women who got married at the age of 25 and 34 had the highest prevalence of current use of FP 48.5(31.9-65.4) and 5.8(1.8-16.6), respectively. In both counties, more employed women were currently using FP compared to unemployed women. 
Table 2

Percentage of women currently using Contraceptive in Lamu and Wajir

\begin{tabular}{|c|c|c|c|c|c|}
\hline & & County & & & \\
\hline & & $\begin{array}{l}\operatorname{Lamu}(n= \\
342)\end{array}$ & & $\begin{array}{l}\text { Wajir }(n= \\
321)\end{array}$ & P-value \\
\hline Current FP (Overall \% prev) & & 32.8 & & 3.4 & \\
\hline Variable & & & & & \\
\hline Age categories (years): & & $\mathrm{n}(\%)$ & & $\mathrm{n}(\%)$ & \\
\hline $18-24$ & $\begin{array}{l}n= \\
342\end{array}$ & $\begin{array}{l}24.7(17.1- \\
34.4)\end{array}$ & $\begin{array}{l}n= \\
321\end{array}$ & $1.3(0.2-8.6)$ & \\
\hline $25-34$ & & $\begin{array}{l}42.9(35.2- \\
50.8)\end{array}$ & & $\begin{array}{l}5.4(2.8- \\
10.0)\end{array}$ & 0.02 \\
\hline $35-44$ & & $\begin{array}{l}24.2(16.4- \\
34.1)\end{array}$ & & 0 & \\
\hline $45+$ & & 0 & & $\begin{array}{l}25.0(2.4- \\
82.1)\end{array}$ & \\
\hline Highest level of education: & & & & & \\
\hline None/Madrassa & $\mathrm{n}=$ & $8.3(1.1-43.7)$ & $\mathrm{n}=$ & $1.2(0.3-4.6)$ & \\
\hline Primary & & $\begin{array}{l}30.5(20.0- \\
43.5)\end{array}$ & & $1.5(0.2-9.9)$ & $\dot{0.0001}$ \\
\hline Secondary and above & & $\begin{array}{l}34.3(28.9- \\
40.2)\end{array}$ & & $\begin{array}{l}9.8(4.9- \\
18.4)\end{array}$ & \\
\hline Marital status: & & & & & \\
\hline Married & $\begin{array}{l}n= \\
342\end{array}$ & $\begin{array}{l}35.2(29.9- \\
40.9)\end{array}$ & $\begin{array}{l}n= \\
321\end{array}$ & $3.8(2.0-6.9)$ & 0.021 \\
\hline Not Married & & $\begin{array}{l}20.0(11.4- \\
32.8)\end{array}$ & & $\begin{array}{l}1.8(0.2- \\
11.9)\end{array}$ & \\
\hline Age at marriage -years : & & & & & \\
\hline$<25$ & $\begin{array}{l}n= \\
342\end{array}$ & $\begin{array}{l}33.6(28.0- \\
39.7)\end{array}$ & $\begin{array}{l}n= \\
321\end{array}$ & $3.3(1.6-6.8)$ & \\
\hline $25-34$ & & $\begin{array}{l}48.5(31.9- \\
65.4)\end{array}$ & & $\begin{array}{l}5.8(1.8- \\
16.6)\end{array}$ & 0.634 \\
\hline$>35$ & & $\begin{array}{l}19.6(11.1- \\
32.3)\end{array}$ & & $\begin{array}{l}1.8(0.2- \\
11.9)\end{array}$ & \\
\hline
\end{tabular}


Currently employed:

\begin{tabular}{|c|c|c|c|c|c|}
\hline Yes & $\begin{array}{l}n= \\
342\end{array}$ & $\begin{array}{l}53.4(40.5- \\
65.9)\end{array}$ & $\begin{array}{l}n= \\
321\end{array}$ & $5.8(1.8,16.6)$ & \\
\hline No & & $\begin{array}{l}28.5(23.5- \\
34.1)\end{array}$ & & $3.0(1.5,5.9)$ & $\begin{array}{l}<.0001 \\
0.01\end{array}$ \\
\hline
\end{tabular}

Ever given birth:

Yes

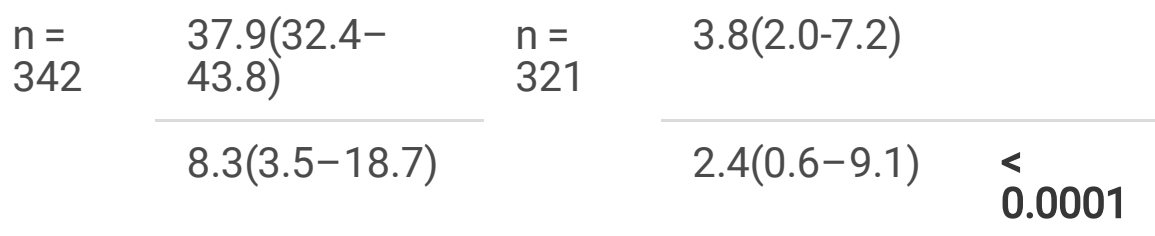

Number of living children :

\begin{tabular}{|c|c|c|c|c|c|}
\hline 0 & $\begin{array}{l}n= \\
235\end{array}$ & $\begin{array}{l}28.6(6.3- \\
70.4)\end{array}$ & $\begin{array}{l}n= \\
215\end{array}$ & $\begin{array}{l}16.7(3.9- \\
49.6)\end{array}$ & \\
\hline 1 & & $\begin{array}{l}34.6(25.0- \\
45.6)\end{array}$ & & $\begin{array}{l}3.6(0.9- \\
13.7)\end{array}$ & 0.007 \\
\hline $2-4$ & & $\begin{array}{l}48.3(39.4- \\
57.4)\end{array}$ & & $\begin{array}{l}5.4(2.2- \\
12.4)\end{array}$ & \\
\hline 5 or more & & $\begin{array}{l}24.1(11.8- \\
43.1)\end{array}$ & & $\begin{array}{l}3.6(0.9- \\
13.7)\end{array}$ & \\
\hline Currently $\mathrm{f}$ & & & & & \\
\hline Yes & $\begin{array}{l}n= \\
342\end{array}$ & $10.4(5.0-20.5)$ & $\begin{array}{l}n= \\
321\end{array}$ & $\begin{array}{l}3.5(0.9- \\
13.2)\end{array}$ & $\begin{array}{l}<.0001 \\
0.00\end{array}$ \\
\hline No & & $\begin{array}{l}38.2(32.6- \\
44.1)\end{array}$ & & 3.4(1.8- & \\
\hline
\end{tabular}

The current pregnancy is first pregnancy :

\begin{tabular}{|c|c|c|c|c|c|}
\hline Yes & $\mathrm{n}=67$ & 0 & $\mathrm{n}=57$ & 0 & 0.029 \\
\hline No & & $\begin{array}{l}14.6(7.0- \\
28.0)\end{array}$ & & $\begin{array}{l}5.7(1.4- \\
21.0)\end{array}$ & \\
\hline
\end{tabular}

Ever discussed with partner on FP use:

\begin{tabular}{|c|c|c|c|c|c|}
\hline Yes & & $\begin{array}{l}46.2(39.3- \\
53.2)\end{array}$ & $\begin{array}{l}n= \\
321\end{array}$ & $\begin{array}{l}6.4(2.7- \\
14.6)\end{array}$ & $\dot{0} 0001$ \\
\hline No & $\begin{array}{l}n= \\
342\end{array}$ & $\begin{array}{l}14.5(10.0- \\
21.2)\end{array}$ & & $2.5(1.1-5.4)$ & \\
\hline
\end{tabular}




\begin{tabular}{|c|c|c|c|c|c|}
\hline \multicolumn{6}{|c|}{ Aware on FP methods: } \\
\hline Yes & \multirow[t]{2}{*}{$\begin{array}{l}n= \\
342\end{array}$} & $\begin{array}{l}33.6(28.7- \\
39.0)\end{array}$ & \multirow[t]{2}{*}{$\begin{array}{l}n= \\
321\end{array}$} & $4.8(2.4-9.3)$ & \multirow[t]{2}{*}{$\begin{array}{l}<.0001 \\
0.00\end{array}$} \\
\hline No & & $\begin{array}{l}19.1(7.1- \\
41.9)\end{array}$ & & $2.0(0.6-5.9)$ & \\
\hline \multicolumn{6}{|c|}{ FP acceptable in culture } \\
\hline Yes & \multirow[t]{2}{*}{$\begin{array}{l}n= \\
341\end{array}$} & $\begin{array}{l}47.7(40.7- \\
54.8)\end{array}$ & \multirow[t]{2}{*}{$\begin{array}{l}n= \\
257\end{array}$} & $\begin{array}{l}5.8(2.8- \\
11.7)\end{array}$ & \\
\hline No & & $\begin{array}{l}13.5(8.9- \\
20.1)\end{array}$ & & $2.2(0.7-6.7)$ & 0.001 \\
\hline \multicolumn{6}{|c|}{ FP is allowed in Islam } \\
\hline Yes & \multirow[t]{2}{*}{$\begin{array}{l}n= \\
324\end{array}$} & $\begin{array}{l}37.0(30.0- \\
44.6)\end{array}$ & \multirow[t]{2}{*}{$\begin{array}{l}n= \\
171\end{array}$} & $\begin{array}{l}13.4(7.1- \\
24.0)\end{array}$ & \\
\hline No & & $\begin{array}{l}29.6(23.0- \\
37.2)\end{array}$ & & $1.6(0.4-6.3)$ & 0.029 \\
\hline \multicolumn{6}{|c|}{ Willingness to obtain Information } \\
\hline Yes & \multirow[t]{2}{*}{$\begin{array}{l}n= \\
342\end{array}$} & $\begin{array}{l}71.2(62.0- \\
78.9)\end{array}$ & \multirow[t]{2}{*}{$\begin{array}{l}n= \\
321\end{array}$} & $\begin{array}{l}6.2(3.2- \\
11.5)\end{array}$ & \\
\hline No & & $\begin{array}{l}14.3(10.3- \\
19.4)\end{array}$ & & $1.1(0.3-4.5)$ & <. 0001 \\
\hline
\end{tabular}

In Lamu, the percentage of employed women currently using FP was 53.5(40.5-66.0), while in Wajir, it was 5.8(1.8-16.6). Women who had ever given birth in Lamu and Wajir were the highest group currently using FP 37.9 (32.4-43.8) vs 3.8 (2.0-7.2) per cent, respectively. In both counties, women who discussed FP use with their partners were current users of FP. In Lamu, the percentage of women currently using FP and discussed this with their partners was 46.2 (39.3-53.2), while in Wajir, it was 6.4 (2.7-14.6). In both counties, women who were aware of FP methods were currently using FP. The percentage of women who were aware and were currently using was 33.6 (28.7-39.0) per cent in Lamu and 4.8 (2.4-9.3) in Wajir. We found that, the highest prevalence of current use of FP was among women who stated that FP use was acceptable in their culture; it was 47.7(40.7-54.8) per cent in Lamu while in Wajir, it was 5.8(2.811.7) per cent. In Lamu, the current use of FP was highest among women who stated that the use of FP is allowed in Islam is 37.0(30.0-44.6). Similarly, in Wajir, current use was highest among women who stated that FP was allowed in Islam, 13.4(7.1-24.0) per cent. The highest prevalence in Lamu and Wajir was among women who were willing to obtain information regarding contraceptives 71.2(62.0-78.9) percent and 6.2(3.2-11.5) percent in Lamu and Wajir respectively.

Reasons For Family Planning Non-use 
A total of $392(59.13 \%)$ study participants reported they have never used any family planning methods. The common reasons for not using family planning methods were: religion disallowing it $(70.6 \%)$, the husband refused to use (22.14\%), and mother-in-law refused (5.73\%). Figure 2 shows the reasons for never using family planning methods.

\section{Determinants Of Current Contraceptive Use}

Table 3 shows the results of a logistic regression analysis of determinants of current FP use. In Lamu, a woman married at 35 years and above is 0.23 times less likely to be a current user compared to women married below 25 years $(\mathrm{AOR}=0.2395 \% \mathrm{Cl}=0.08-0.68)$. The odds of the current use of $\mathrm{FP}$ is significantly higher for those in current employment compared to the unemployed $(\mathrm{AOR}=3.0695 \% \mathrm{Cl}=$ 1.30-7.19). Those who have even discussed FP with their partners are more likely to be current users of family planning $(A O R=2.6395 \% \mathrm{Cl}=1.25-5.53)$. Women who believed that family planning is acceptable in their culture are more likely to be current users of family planning compared to those who don't (AOR $=5.0095 \% \mathrm{Cl}=2.38-10.49)$. The odds of the current use of FP is significantly higher for those who are willing to obtain information compared to those not willing to obtain information ( $A O R=20.04$ $95 \% \mathrm{Cl}=9.77-41.10)$. In Wajir, factors identified as determinants of the current use of family planning were education level, FP allowed in Islam and willingness to obtain information. A woman with secondary level of education and above is 7.39 times more likely to be a current family planning user compared to women with no education ( $\mathrm{AOR}=7.3995 \% \mathrm{Cl}=1.42-38.60)$. Women who believed that family planning is allowed in Islam are more likely to be current users of family planning compared to those who don't ( $A O R=9.4795 \% \mathrm{Cl}=1.98-45.21)$. The odds of the current use of FP is significantly higher for those who are willing to obtain information compared to those not willing to obtain information ( $A O R=2.8895 \% \mathrm{Cl}$ $=0.52=15.94)$. 
Table 3

Determinants of current use of contraception $(n=663)$

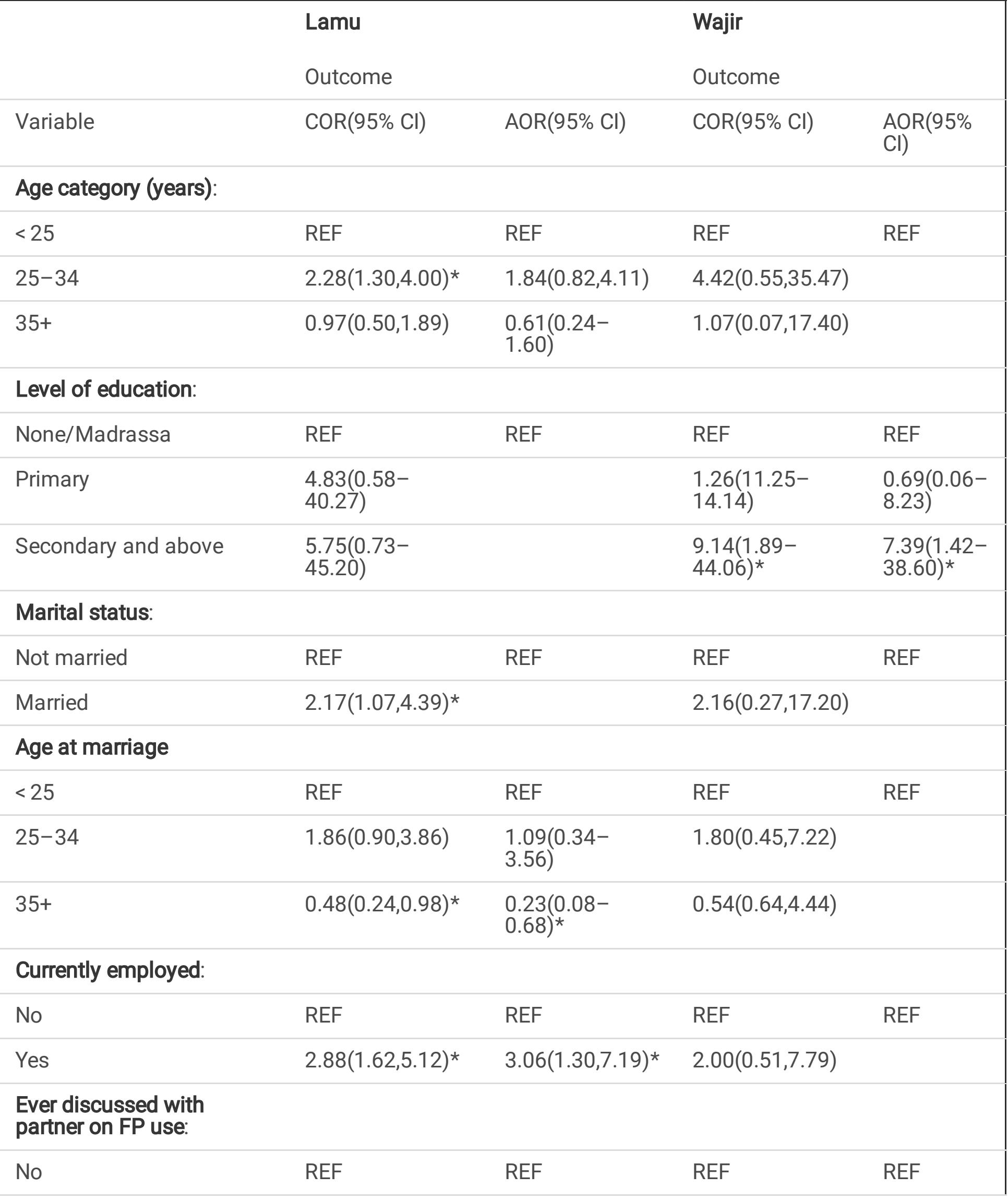




\begin{tabular}{|c|c|c|}
\hline Yes & $5.07(2.95,8.70)$ * & $\begin{array}{l}2.63(1.25- \\
5.53)^{\star}\end{array}$ \\
\hline
\end{tabular}

\section{Ever given birth:}

$\begin{array}{lllll}\text { No } & \text { REF } & \text { REF } & \text { REF } & \text { REF } \\ \text { Yes } & 6.73(2.61,17.33)^{*} & \begin{array}{l}2.56(0.78- \\ 8.48)\end{array} & 1.62(0.34,7.65) & \\ & & & \end{array}$

\section{Number of living children}

$(\mathrm{N}=431)$ :

\begin{tabular}{lllll}
0 & REF & REF & REF & REF \\
1 & $1.32(0.24-7.25)$ & $0.19(0.02-1.50)$ \\
$2-4$ & $2.34(0.44-$ & $0.28(0.05-1.66)$ \\
& $12.52)$ & \\
\hline 5 or more & $0.80(12.54-$ & $0.19(0.02-1.50)$ \\
& $5.05)$ &
\end{tabular}

\section{FP awareness}

$\begin{array}{llll}\text { No } & \text { REF } & \text { REF } & \text { REF } \\ \text { Yes } & 2.15(0.71,6.56) & & 2.5(0.65,9.60)\end{array}$

\section{FP acceptable in my culture:}

$\begin{array}{lllll}\text { No } & \text { REF } & \text { REF } & \text { REF } & \text { REF } \\ \text { Yes } & 5.83(3.37- & 5.00(2.38- & 2.72(0.69- & \\ & 10.10)^{*} & 10.49)^{*} & 10.77) & \end{array}$

FP is allowed in Islam:

\begin{tabular}{lllll} 
No & REF & REF & REF & REF \\
Yes & $1.40(0.88-2.22)$ & & $\begin{array}{l}9.47(1.98- \\
45.21)^{\star}\end{array}$ & $\begin{array}{l}8.36(1.55- \\
45.01)\end{array}$ \\
Willingness & & & & \\
No & & & REF & REF \\
Yes & REF & REF & $5.76(1.22-$ & $2.88(0.52-$ \\
& $14.81(8.53-$ & $20.04(9.77-$ & $27.09)$ & $15.94)$ \\
\hline
\end{tabular}

Values in * show significance at $p$-value $<0.05$

Discussion 
This study aimed to determine the pattern and determinants of contraceptive use among women in Wajir and Lamu County in Kenya. The percentage of the current use of FP in Lamu was $32.8 \%$ while in Wajir, it was $3.4 \%$ percent. This finding is similar to the $2014 \mathrm{KDHS}$ results (5)

The findings illustrate that current contraceptive use in Lamu was significantly influenced by; employment, discussion of Family Planning with a partner and ever given birth. In Wajir, the significant factors were; education, discussion with partner; FP allowed in Islam and willingness to obtain information on FP.

The study results also revealed that in both counties injectable were the most common method of contraception (54.6 percent). This was then followed by pills (46.9 percent) and implants (18.1 percent). These finding are similar to the KDHS 2014 report and a study conducted in Ghana that revealed that injectable are the most common family planning method among women $(5,25)$. The preference for injectable could be attributed to lack of partner support and the fact that injectable can be used covertly. In one qualitative study conducted in Ghana, respondents reported that uptake of family planning is associated with promiscuity and this could explain why most women in this study preferred the use of injectable (26)

The descriptive analysis show that $59.13 \%$ of the respondent indicated that they have never used any FP method. The highest proportion of those who indicated to have never use any contraptive method were from Wajir county $79.13 \%$. The leading reason for non-use were; religion disallowing FP use (70.6\%) and husband's disapproval (22.14\%). The notion that Islam does not permit the use of FP could be one of the reasons for low contraceptive use among women in Wajir with $68 \%$ of the respondent indicating Islam is against the use of FP. The misconception that Islam does not allow FP use has been documented in other studies (27-30). The influence of men in women's ability to decide whether to use contraception is evident from our results. This depicts the dominance of men in decision making in patriarchal African society. Lamu and Wajir County are regions that have highly placed patriarchal systems and values that do not support the independence and free decision making of women regarding their reproductive health. These findings are comparable to an earlier qualitative study conducted in the two counties $(19,28)$.

Our results show that, married women in Lamu are nearly three times more likely to be current users of family planning compared to non-married women. This is consistent with a study conducted in Kenya, Uganda and the $2014 \mathrm{KDHS}$ report that states that 53 per cent of currently married women using contraceptives $(5,17,31)$. Contraceptive use is high among married women because they are more likely to be sexually active. In addition to that, they are at high risk of getting unplanned pregnancies.

The odds of current use of family planning is higher among women who are currently employed in Lamu compared to those who are unemployed. This is consistent with other studies conducted that focused on the determinants and prevalence of contraception use among employed and unemployed women $(6,32)$. Employed women are more likely to use contraception because they have more negotiation power on contraceptive use. 
Our findings demonstrate that in both study sites, women who discussed FP with their partners are more likely to be current users of contraceptive. Our results are in agreement with several studies that show direct relation between FP use and discussion with partner $(25,33,34)$. A study done in southeast Ethiopia revealed that opposition to modern family planning by spouses determined whether they used contraception (35).

The findings revealed that in Wajir, women who were above the secondary level of education were more likely to be current users of FP compared to those who had not. This is consistent with several studies $(6,12)$. These results could be explained by the fact that, educated women are more informed about their reproductive health, and the benefits and the side effects that come with the use of family planning. Educated women are also empowered, giving them more authority to make decisions regarding their reproductive health. Wajir county has one of the lowest educational attainment levels in Kenya with as many as $76 \%$ of its residents having low education levels and only $4 \%$ have completed secondary level education or higher (23). The low education level particularly for women and girls could be one of contributing factors to low uptake of Family planning in Wajir county.

The results also revealed that in Lamu acceptability of FP in culture was a key determinant of FP utilization while in Wajir permissibility of FP in Islam was a key determinant of FP uptake. Many studies and analytical reviews show that Islam allows the use of family planning within the confines of marriage. These studies used the sources of Islamic Sharia to justify the permissibility of FP $(20,36,37)$.

Although our study has unearthed some key factors that determine Family planning uptake among Muslim women in the two counties, it is worth noting that this study had its own limitations. Like many other cross sectionals studies, we were not able to measure cause and effect relationship. However, despite this shortcoming, the paper provides an interesting contribution in understanding the pattern and determinates of family planning uptake among Muslim communities in an area that has not been fully explored in the Kenyan context.

\section{Conclusion And Recommendation}

We found moderately high use of contraceptive use among women of reproductive age in Lamu county and very low current contraceptive use among women in Wajir. Discussion with partner has come out as a key determinant for FP use in both counties. These findings reflect the need for family planning programs to address issues of male involvement in reproductive health programmes given the patriarchal nature of the two communities. Education has shown to be a key determinant in decision-making on contraceptive use particularly in Wajir which has one of the lowest education attainment levels in the country, and thus it is important for the national and county government to invest in education, particularly for women and girls to enhance their ability to make informed decisions. Further, our findings highlight the need to develop culturally appropriate messages and involvement of religious leaders to demystify the myths and misconception around family planning and Islam. It worth exploring inter- 
county learning and exchange programme for Wajir County to learn from Lamu given the homogeneity in religious beliefs.

\section{Abbreviations}

CPR: Contraceptive prevalence rate;

DHS: Demographic and health survey;

FP: Family Planning;

KDHS: Kenya demographic and health survey;

MICS: Multiple Indicator Cluster Survey;

NACOSTI: National Commission for Science, Technology and Innovation

TRF: Total fertility Rate.

UNFPA: United Nations Population Fund

\section{Declarations}

\section{Ethics approval and consent to participate}

Ethical approval for the study was obtained from the Research Ethics Committee of the Aga Khan University, Nairobi (2016/REC-56 (v3)). We also obtained a research permit from the National Commission for Science, Technology and Innovation (NACOTI/P/18/14340/20946) to facilitate the conduct of research activities in the community. All participants provided consent after being informed about the objective of the study.

\section{Consent for publication}

Not applicable

\section{Availability of data and materials}

The datasets used to analyze the current study are available from the corresponding author on reasonable request.

\section{Competing interests}

The authors declare that they have no competing interests. 


\section{Funding}

This research was partially funded by UNFPA Kenya country office specifically the data collection for Wajir County.

\section{Author's contribution}

BA conceptualized and designed the study. As principal investigator, BA was responsible for all aspects of data collection analysis, and writing of the initial manuscript draft. MT, GS, PG and JO provided overall guidance in the interpretation of the findings, reviewed the manuscript and edited drafts and added substantive intellectual content with particular attention on how it adds to the body of knowledge. VW supported with statistical analysis and interpretation. All authors read and approved the final manuscript.

\section{Author's information}

BA is a PhD student at Ghent University in Belgium and also Policy advisor at UNFPA Uganda Country office. JO is Senior Research Associate at Population Council- Kenya. GS is Prof of OB/GYN and Director International Islamic Center for Population Studies and Research, Al Azhar University, Cairo Egypt. PG is a professor at department Obstetrics and Gynecology, Ghent University, Belgium and Deputy vice chancellor at technical university of Mombasa, Kenya. MT is a Professor and MD, at the Ghent University, Faculty of Medicine and Health Sciences and also Director Centre of Excellence Women and Child Health, Aga Khan University, Kenya

\section{Acknowledgement}

The authors are grateful to the county health teams of Wajir and Lamu, interview participants, research field staff for their willingness to participate in and support this study.

\section{Ethics approval and consent to participate}

The study was conducted in accordance with the principles of the Declaration of Helsinki. Ethical approval for the study was obtained from the Research Ethics Committee of the Aga Khan University, Nairobi (2016/REC-56 (v3)). We also obtained a research permit from the National Commission for Science, Technology and Innovation (NACOTI/P/18/14340/20946) to facilitate the conduct of research activities in the community. All participants provided written informed consent after being informed about the objective of the study.

\section{References}

1. United N. World Family Planning [Highlights]. 2017;1-43.

2. United Nation Department of Economic and Social Affairs Population Divison. Trends in contraceptive use Worldwide 2015 [Internet]. Contraception. 2015. 1-70 p. Available from: 
http://dx.doi.org/10.1016/j.contraception.2012.08.029

3. Cleland J, Conde-Agudelo A, Peterson H, Ross J, Tsui A. Contraception and health. Lancet [Internet]. 2012;380(9837):149-56. Available from: http://dx.doi.org/10.1016/S0140-6736(12)60609-6

4. Susheela Singh JEDJED. Adding It Up: Costs and Benefits of Contraceptive Services. Guttmacher Inst UNFPA [Internet]. 2012; Available from: https://www.popline.org/node/536252

5. Kenya National Bureau of statistics. Kenya Demographic and Health Survey (KDHS) 2014-15. 2014;

6. Islam AZ. Factors affecting modern contraceptive use among fecund young women in Bangladesh: Does couples' joint participation in household decision making matter? Reprod Health. 2018;15(1):1-9.

7. Monica. A. M, Sian.L. C. Trends and determinants of contraceptive method choice in Kenya. Stud Fam Plann [Internet]. 2003;34(3):149-59.

8. Kimani M. Trends in Contraceptive Use in Kenya, 1989-1998: The Role of Socio-economic, Cultural and Family Planning Factors. African Popul Stud. 2013 Oct;21(2).

9. Kenya National Bureau of Statistics. Kenya Demographic and Health Survey 2014: 47 Counties Fact Sheet. 2014;(1):1-94.

10. Mekonnen W, Worku A. Determinants of low family planning use and high unmet need in Butajira District, South Central Ethiopia. Reprod Health. 2011;8(1):1-8.

11. Kabir H, Saha NC, Oliveras E, Gazi R. Association of programmatic factors with low contraceptive prevalence rates in a rural area of Bangladesh. Reprod Health. 2013;10(1):4-11.

12. Ikamari LDE. The effect of education on the timing of marriage in Kenya. Demogr Res. 2005;12:128.

13. Ibrahim HA. Determinants of birth control use among Kenyan women: evidence from DHS-20082009. African J Sci Res [Internet]. 2016;5(1):1-5.

14. Saleem S, Bobak M. Women's autonomy, education and contraception use in Pakistan: A national study. Reprod Health. 2005;2(1):1-8.

15. Mohammed A, Woldeyohannes D, Feleke A, Megabiaw B. Determinants of modern contraceptive utilization among married women of reproductive age group in North Shoa Zone, Amhara Region, Ethiopia. Reprod Health. 2014;11(1):1-7.

16. Mosha I, Ruben R, Kakoko D. Family planning decisions, perceptions and gender dynamics among couples in Mwanza, Tanzania: a qualitative study. BMC Public Health. 2013 Dec;13(1):523.

17. Kabagenyi A, Reid A, Ntozi J, Atuyambe L. Socio-cultural inhibitors to use of modern contraceptive techniques in rural Uganda: a qualitative study. Pan Afr Med J. 2016;25:78.

18. Author K, Rutenberg N, Cotts Watkins S. The Buzz Outside the Clinics: Conversations and Contraception in Nyanza Province. Vol. 28, Family Planning. 1997.

19. Abdi B, Okal J, Serour G, Temmerman M. " Children are a blessing from God " - a qualitative study exploring the socio- cultural factors influencing contraceptive use in two Muslim communities in Kenya. 2020;1-11. 
20. Omran AR. Family planning in the legacy of Islam. Routledge; 1992. 284 p.

21. Roudi-fahimi F. Islam and Family Planning. Popul Ref Bur MENA Policy Br. 2004;1-8.

22. Mahadeen Al, Khalil AO, Hamdan-Mansour AM, Sato T, Imoto A. Knowledge, attitudes and practices towards family planning among women in the rural southern region of Jordan. East Mediterr Health J. 2012 Jun;18(6):567-72.

23. Njonjo KS. "Exploring Kenya 's Inequality: Pulling Apart of Pooling Together". Abriged report [Internet]. 2013. Available from: http://inequalities.sidint.net/kenya/wpcontent/uploads/sites/3/2013/10/SID Abridged Small Version Final Download Report.pdf

24. Yozgatligil CT, Ayhan HÖ. Univariate sample size determination by alternative components: Issues on design efficiency for complex samples. Stat Transit. 2018;19(2):201-18.

25. Beson $P$, Appiah R, Adomah-Afari A. Modern contraceptive use among reproductive-aged women in Ghana: Prevalence, predictors, and policy implications. BMC Womens Health. 2018;18(1):1-8.

26. Adongo PB, Tabong PTN, Azongo TB, Phillips JF, Sheff MC, Stone AE, et al. A comparative qualitative study of misconceptions associated with contraceptive use in southern and northern Ghana. Front Public Heal. 2014;2(SEP).

27. Abdi B, Okal J, Serour G, Temmerman M. "children are a blessing from God"- A qualitative study exploring the socio-cultural factors influencing contraceptive use in two Muslim communities in Kenya. Reprod Health. 2020;17(1).

28. Abdi B, Okal J, Serour G, Temmerman M. Muslim men's perceptions and attitudes on family planning: a qualitative study in Wajir and Lamu counties in Kenya. Sex Reprod Heal Matters. 2021;29(1).

29. Degni F, Koivusilta L, Ojanlatva A. Attitudes towards and perceptions about contraceptive use among married refugee women of Somali descent living in Finland. Eur J Contracept Reprod Heal Care. 2006 Sep;11(3):190-6.

30. Degni F, Mazengo C, Vaskilampi T, Essén B. Religious beliefs prevailing among Somali men living in Finland regarding the use of the condom by men and that of other forms of contraception by women. Eur J Contracept Reprod Heal Care. 2008;13(3):298-303.

31. Ochako R, Mbondo M, Aloo S, Kaimenyi S, Thompson R, Temmerman M, et al. Barriers to modern contraceptive methods uptake among young women in Kenya: A qualitative study Global Health. BMC Public Health. 2015;15(1):1-9.

32. Hossain $M$, Khan $M$, Ababneh F, Shaw J. Identifying factors influencing contraceptive use in Bangladesh: Evidence from BDHS 2014 data. BMC Public Health. 2018;18(1):1-14.

33. Tilahun T, Coene G, Temmerman M, Degomme O. Spousal discordance on fertility preference and its effect on contraceptive practice among married couples in Jimma zone, Ethiopia. Reprod Health. 2014 Dec;11(1):27.

34. Eliason S, Awoonor-Williams JK, Eliason C, Novignon J, Nonvignon J, Aikins M. Determinants of modern family planning use among women of reproductive age in the Nkwanta district of Ghana: $A$ case-control study. Reprod Health. 2014;11(1):1-10. 
35. Gonie A, Wudneh A, Nigatu D, Dendir Z. Determinants of family planning use among married women in bale eco-region, Southeast Ethiopia: A community based study. BMC Womens Health. 2018;18(1):1-10.

36. World Faiths Development Dialogue. Religious Engagement in Family Planning Policies: Experience in Six Muslim-majority Countries. 2015.

37. El Hamri N. Approaches to family planning in Muslim communities. J Fam Plan Reprod Heal Care. 2010;36(1):27-31.

\section{Figures}

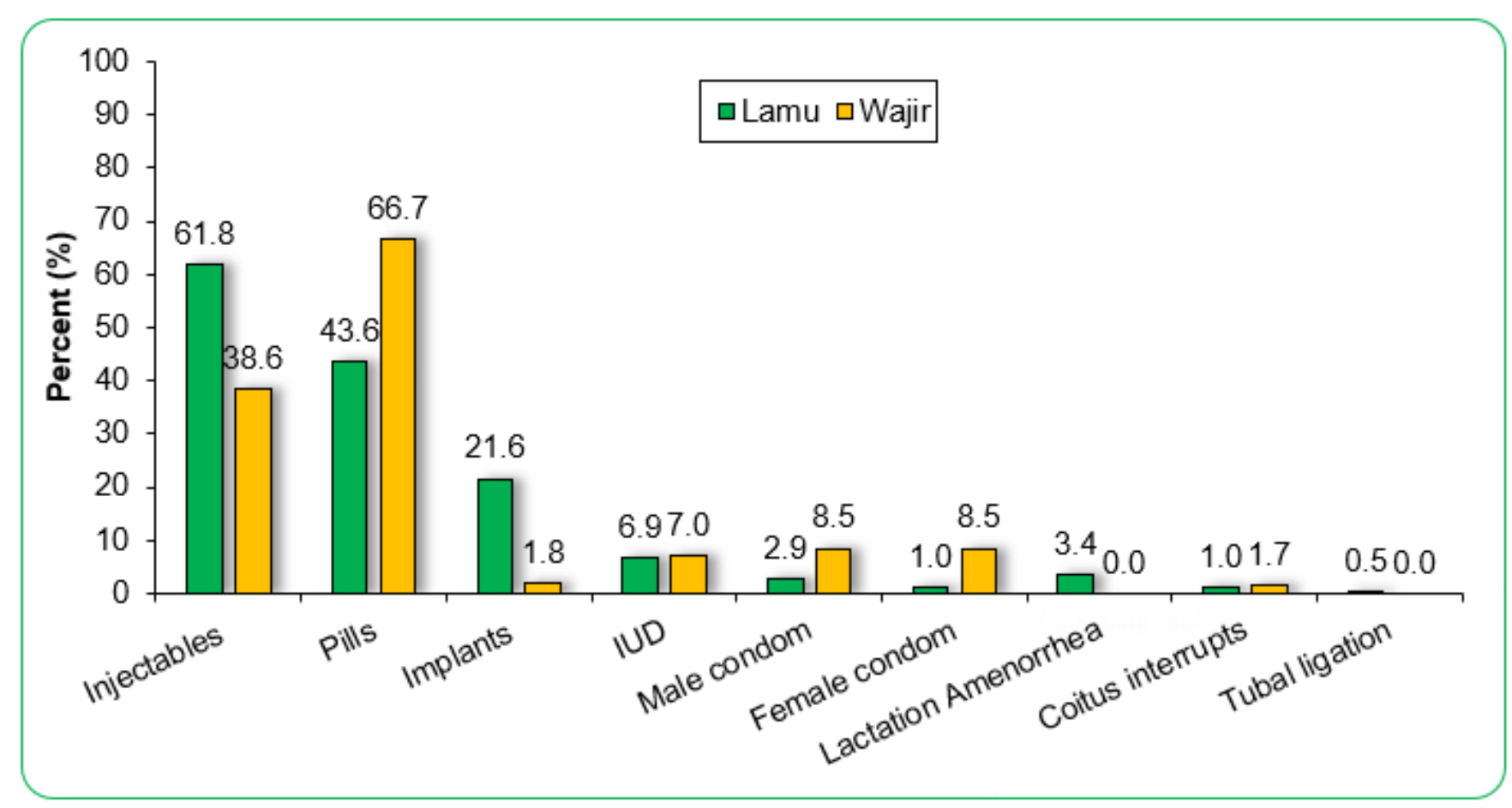

Figure 1

Types of family planning methods used by county of residence $(\mathrm{N}=\mathbf{2 7 1})$. 


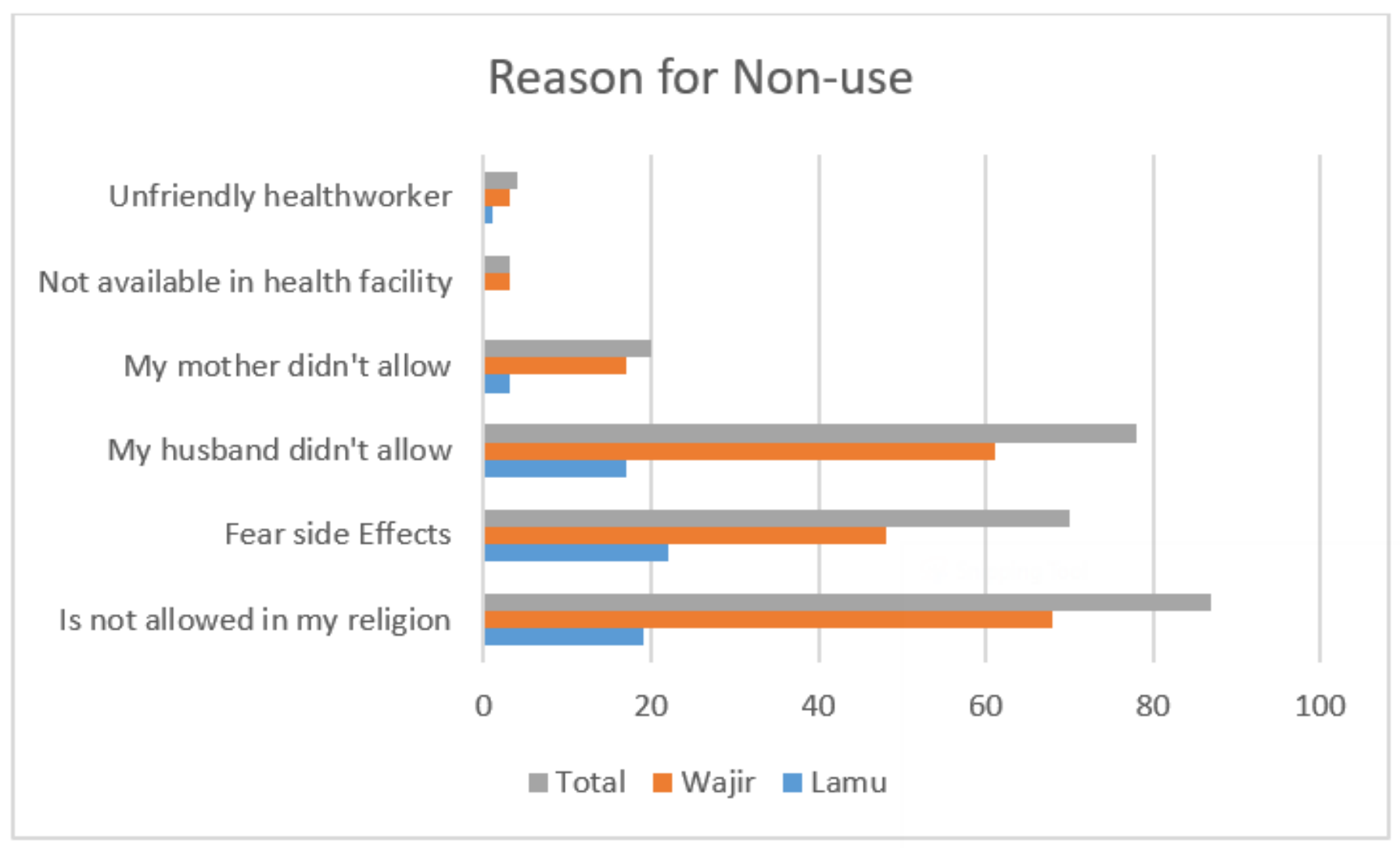

Figure 2

Reasons for Non-use

\section{Supplementary Files}

This is a list of supplementary files associated with this preprint. Click to download.

- AdditionalFile1.doc 